\title{
ÍNDICE DE SUSTENTABILIDADE GLOBAL APLICADO NA AVALIAÇ̃̃O DO ASSENTAMENTO EXPEDITO RIBEIRO, SANTA BÁRBARA - PA
}

\author{
Paulo Amador Tavares ${ }^{1}$ \\ Yuri Cavaleiro de Macêdo Coelho ${ }^{2}$ \\ Andreza Mesquita Martins ${ }^{3}$ \\ Norma Ely Santos Beltrão ${ }^{4}$ \\ Ana Lúcia Nunes Gutjahr ${ }^{5}$ \\ Manoel Tavares de Paula ${ }^{6}$
}

\begin{abstract}
RESUMO
Os assentamentos humanos em localidades próximas a grandes centros urbanos podem ser considerados como interessantes alternativas para a promoção do desenvolvimento sustentável a famílias de baixa renda. A aplicação de Sistemas Agroflorestais (SAFs), nessas áreas, quando aparada por suporte técnico, pode mostrar aos habitantes oportunidades para o seu desenvolvimento econômico e social com impactos menos agressivos ao ambiente. Nessa perspectiva, o artigo objetivou analisar, a partir de indicadores, o nível de sustentabilidade do Assentamento Expedito Ribeiro, Santa Barbara, Pará, onde iniciativas institucionais estimulam a implantação de SAFs. Para isso, aplicou-se o método de avaliação do Índice de Sustentabilidade Global (ISG) que avalia as quatro dimensões: ambiental, social, institucional e econômica, através de formulários estruturados dirigidos aos habitantes locais e observação participante. Notou-se que os indicadores com maiores valores encontrados de sustentabilidade foram os de cunho institucional $(0,89)$ e ambiental $(0,74)$, seguidos do social $(0,60)$ e econômico $(0,59)$. A partir disso, obteve-se ISG igual a 0,70 , o que qualifica o assentamento como aceitável na escala de sustentabilidade do PNUD/ONU. Neste contexto, ainda que a área de estudo não tenha alcançado os números ideais estabelecidos, os valores encontrados são superiores aos calculados por outros estudos realizados na região amazônica. Isso evidencia que o incentivo e o desenvolvimento de SAFs nas localidades beneficiam não somente variáveis ambientais, mas também o desenvolvimento social e econômico dos habitantes.
\end{abstract}

Palavras-chave: Assentamentos Rurais. Sistemas Agroflorestais. Desenvolvimento Sustentável.

${ }^{1}$ Bolsista CAPES e mestranda do Programa de Pós-Graduação em Ciências Ambientais da Universidade do Estado do Pará (UEPA). Universidade do Estado do Pará (UEPA). Brasil. E-mail: atavares.paulo@gmail.com

${ }^{2}$ Mestrando no Programa de Pós-Graduação em Ciências Ambientais, na UEPA. Universidade do Estado do Pará (UEPA). Brasil. E-mail: yuricoelhos15@hotmail.com

${ }^{3}$ Possui graduação em Licenciatura em Ciências Naturais - Química, pela UEPA. Universidade do Estado do Pará (UEPA). Brasil. E-mail: andrezamarttins@hotmail.com

${ }^{4}$ Possui doutorado em Economia Agrícola na Justus-Liebig-Universität Giessen na Alemanha (2008), reconhecido pela Universidade Federal do Rio Grande do Sul (UFRGS) como Doutorado em Desenvolvimento Rural. Atualmente é Professora Adjunta da UEPA. Universidade do Estado do Pará (UEPA). Brasil. E-mail: normaelybeltrao@gmail.com

${ }^{5}$ Possui doutorado em Ciências Biológicas e é Professora Adjunta da UEPA. Universidade do Estado do Pará (UEPA). Brasil. E-mail: melcam@uol.com.br

${ }^{6}$ Possui doutorado em Ciências Agrárias e atualmente atua como Professor do curso de Graduação em Engenharia Florestal e do Mestrado em Ciências Ambientais da UEPA. Universidade do Estado do Pará (UEPA). Brasil. E-mail: dpaulamt $@$ hotmail.com

DRd - Desenvolvimento Regional em debate (ISSNe 2237-9029)

v. 9, p. 59-76, 2019 


\title{
ASSESSING THE GLOBAL SUSTAINABILITY INDEX OF THE EXPEDITO RIBEIRO SETTLEMENT, SANTA BÁRBARA-PA
}

\begin{abstract}
Human settlements in locations close to large urban centres can be considered as interesting alternatives for promoting sustainable development for low-income families. The application of Agroforestry Systems (AFS) in these areas when trimmed by technical support, can show people opportunities for their economic and social development with less aggressive impacts to the environment. In this sense, the article aimed to analyse, based on indicators, the level of sustainability of the Expedito Ribeiro settlement, Santa Barbara, Pará, where institutional initiatives stimulate the deployment of AFS. For this, we applied the Global Sustainability Index evaluation method (ISG) which evaluates four dimensions: environmental, social, institutional and economic, through structured forms aimed at locals and participant observation. It was observed that the indicators with the highest values of sustainability were those of institutional (0.89) and environmental (0.74), followed by social (0.60) and economic (0.59). From this, an ISG of 0.70 was obtained, which qualifies the settlement as acceptable in the UNDP/UN sustainability scale. Therefore, although the study area has not reached the ideal numbers established, the values found are higher than those calculated by other studies carried out in the Amazon region. Thus, this shows that the incentive and the development of SAFs in the localities benefit not only environmental variables but also the social and economic growth of the inhabitants.
\end{abstract}

Keywords: Rural Settlements. Agroforestry Systems. Sustainable Development.

\section{INTRODUÇÃO}

Dentro do amplo conceito de desenvolvimento sustentável, ênfase tem sido dada à busca do equilíbrio entre o crescimento econômico e a manutenção dos recursos naturais, com inúmeras oportunidades para promover soluções baseadas na natureza nas áreas de produção de alimentos, agroecologia e uso de recursos renováveis (MAES; JACOBS, 2015). Apesar dos crescentes avanços metodológicos e de inovações tecnológicas, não se ignora o processo contínuo de fortalecimento dos pilares do desenvolvimento sustentável nas suas três dimensões (econômica, ambiental e social) nos níveis local, regional, nacional e global (SINGH, 2014). Nesse contexto, depreende-se que, para alcançar a sustentabilidade é preciso ter a participação de toda a população, assim como considerar as diferentes dimensões do desenvolvimento sustentável (BENETTI, 2006).

A avaliação do progresso em direção aos objetivos do desenvolvimento sustentável tem sido uma preocupação desde a publicação da Agenda 21, em 1992, quando defendeu a necessidade de indicadores para fornecer bases sólidas para a tomada de decisão em todos os níveis (HOLDEN et al., 2016). Desde então, inúmeros indicadores, conjunto de indicadores e metodologias tem sido utilizados no monitoramento da operacionalização do desenvolvimento sustentável, fornecendo uma ferramenta de suporte para o processo de decisão e formulação de políticas e práticas sustentáveis (GOMES; MALHEIROS, 2012). 
Os indicadores de sustentabilidade têm como principal função fornecer informações sobre diversas dimensões: ambientais, econômicas, socioeconômicas, culturais, institucionais, etc. (CARVALHO, et al., 2011; RABELO; LIMA, 2007; FRANCA, 2001), e devem ser selecionados de tal maneira que compreendam os fenômenos que ocorrem no local de estudo. Por avaliarem o estado da sustentabilidade, cujos valores variam de estudo para estudo, são elaboradas adaptações a fim de que a validade dos dados possa ser constatada e os resultados encontrados não sejam enviesados (MORA; LINARES, 2014; FEIL; SCHREIBER, 2017). Abordagens como a do nexo entre água-alimentos-energia (ENDO et al., 2017; LARCOM; VAN GEVELT, 2017), as análises de pressão-impacto-estado-resposta (NERI et al., 2016; BURKHARD; MÜLLER, 2008), e o desenvolvimento de índices de sustentabilidade (GEIJZENDORFFER et al., 2017; FERREIRA et al., 2017), são excelentes alternativas para avaliar a situação e o que pode ser melhorado em uma determinada região ou situação.

A avaliação da sustentabilidade e os indicadores de sustentabilidade são, portanto, ferramentas de apoio à tomada de decisão que tem um importante papel nos desafios estratégicos de interpretar, estruturar informação e influenciar decisões voltadas à implementação do desenvolvimento sustentável. Especialmente na esfera governamental com a contribuição dos indicadores de sustentabilidade na aferição dimensional de políticas públicas (SINGH et al., 2007; WAAS et al., 2014; CARVALHO; SILVA, 2015).

No estado do Pará, destacam-se estudos de Rêgo (2013) e Ferreira et al. (2017), que buscaram compreender o funcionamento de comunidades e sua relação com o ambiente, através do Índice de Sustentabilidade Global (ISG). O estudo de Rêgo (2013) foi desenvolvido na ilha do Combú, que faz parte da área de Belém-PA e o estudo de Ferreira et al. (2017) foi desenvolvido em uma área quilombola em Abaetetuba-PA, chamada África. Nessas duas áreas de estudo, é possível perceber que as principais fontes de renda das comunidades estão diretamente ligadas à agricultura e ao extrativismo convencionais.

Neste trabalho, busca-se testar a aplicação de indicadores de sustentabilidade em uma localidade cujas atividades produtivas diferem dos estudos citados. Para isso, selecionou-se como área de estudo o assentamento Expedito Ribeiro, localizado no município de Santa Bárbara, que tem como atividades principais a agricultura familiar e os Sistemas Agroflorestais (SAFs). De acordo com Almeida et al. (2002) e Bandy et al. (1994), essas atividades são alternativas de uso sustentável do ecossistema, sendo consideradas como modelos de exploração da terra, pois apresentam grande aproximação ecológica da floresta natural.

Tendo esse quadro como referência, este estudo tem como objetivo analisar, a partir de indicadores, o nível de sustentabilidade do Assentamento Expedito Ribeiro localizado no município de Santa Barbara-PA, que desenvolve agricultura familiar e Sistemas Agroflorestais, considerados intermediários entre o extrativismo e a agricultura convencional. Assim, podendo comparar o nível de sustentabilidade com outras atividades estudadas e localizadas na mesma região. 


\section{MATERIAIS E MÉTODOS}

\section{1 ÁREA DE ESTUDO}

O estudo foi realizado no Assentamento dos Trabalhadores Rurais Agroecológico Expedito Ribeiro, situado no município de Santa Bárbara, Estado do Pará (Figura 1). O município de Santa Bárbara está localizado na Mesorregião Metropolitana de Belém

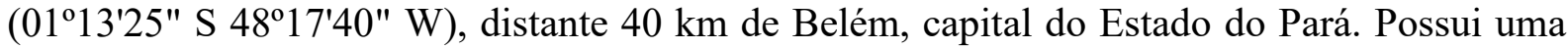
área municipal de $278,154 \mathrm{~km}^{2}$, e abriga uma população de 17.141 habitantes, dos quais $31,84 \%$ estão na área urbana e $68,16 \%$ na área rural, com densidade demográfica de 61,62 hab./Km² (IBGE, 2010).

Figura 1 - Localização das Unidades Familiares consultadas no Assentamento Expedito Ribeiro, Santa BárbaraPA
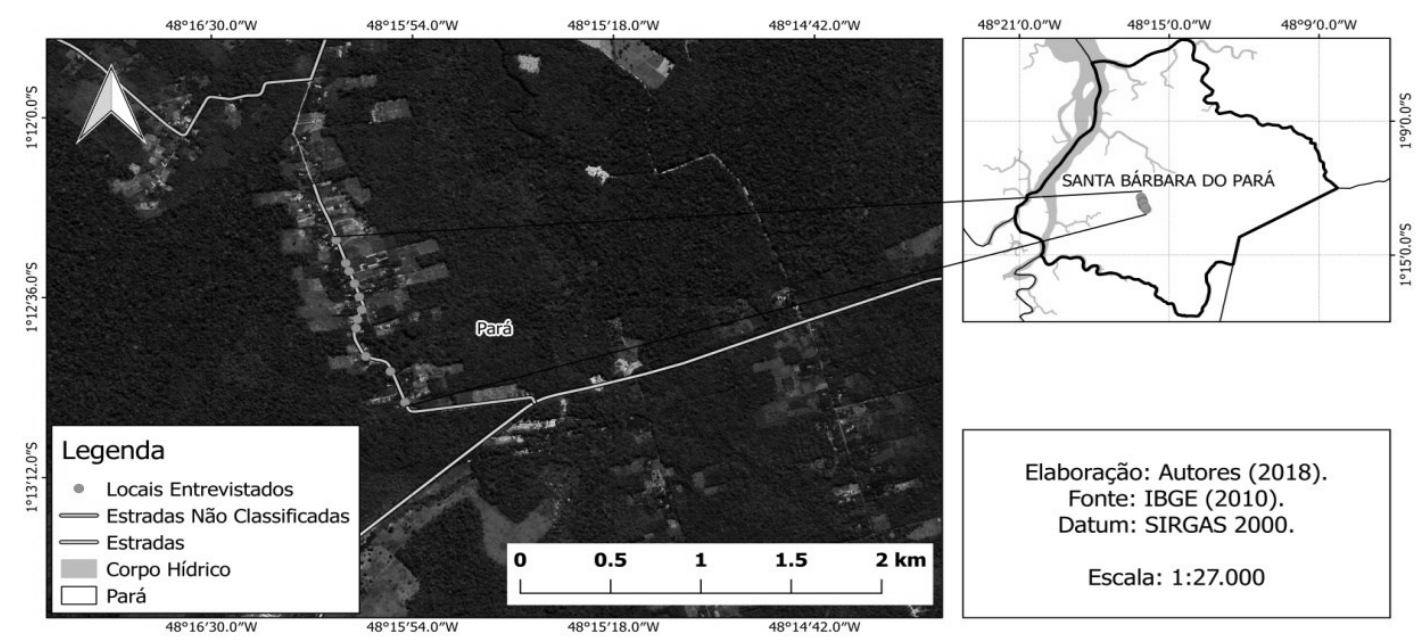

Fonte: Autores (2017).

O acesso ao assentamento é feito pela Rodovia PA-341, sendo necessário acessar posteriormente a entrada de Genipabu. $\mathrm{O}$ assentamento possui abrangência aproximada de 600 hectares, dos quais cerca $80 \%$ são de área verde que constituem a reserva legal (FONSECA et al., 2015). Segundo informações da associação de moradores do assentamento, estão domiciliadas 54 famílias nessa área.

\subsection{COLETA DOS DADOS}

A coleta de dados foi realizada por meio da aplicação de formulários estruturados, preenchidos pelo pesquisador, com questões 16 fechadas, que compuseram a matriz para

DRd - Desenvolvimento Regional em debate (ISSNe 2237-9029) 
mensurar o ISG, e 8 abertas, que solicitavam explicações mais detalhadas de temáticas inseridas na matriz. Para facilitar a interpretação dos dados, a matriz de indicadores foi elaborada visando respostas dicotômicas sem subcamadas, ou de acordo com uma escala de Likert de cinco pontos, sendo que apenas para o indicador 1 da dimensão Econômica foi utilizado padrão diferenciado (Quadro 2). Em geral, os itens do formulário visavam levantar informações sociodemográficas, bem como a percepção sobre a qualidade das condições ambientais e sociais; as atividades econômicas realizadas no assentamento; e o auxílio institucional ofertado pelo poder público ou iniciativas privadas para o desenvolvimento e subsistência do assentamento.

A técnica observação participante também foi aplicada (ALBUQUERQUE; LUCENA; LINS-NETO, 2010) e oportunizou maior envolvimento dos pesquisadores com os assentados em seus modos de vida, além de auxiliar na recolha de informações através de registros fotográficos, gravações de conversas informais e anotações em caderno de campo.

Os moradores abordados por esse estudo, em totalidade, assinaram um Termo de Consentimento Livre e Esclarecido - TCLE, elaborado com base na Resolução 466/2012 do Ministério da Saúde, concordando em colaborar na coleta de informações sobre suas realidades e conhecimentos, com a garantia do anonimato.

O universo amostral deste estudo considerou um representante de cada família do assentamento, com faixa etária igual ou superior a 18 anos, admitindo-se o coeficiente de segurança de $90 \%$ e margem de erro de 7\%. A amostragem deste estudo foi do tipo nãoprobabilística do tipo racional (ALBUQUERQUE; LUCENA; LINS-NETO, 2010).

\subsection{TRATAMENTO DOS DADOS}

A determinação do grau de sustentabilidade do assentamento estudado ocorreu através da avaliação de quatro dimensões, considerando os indicadores: ambiental, social, econômico e institucional. Para qualificação da sustentabilidade, empregou-se, após adaptações, os valores tabelados propostos pelo Programa das Nações Unidas para o Desenvolvimento (PNUD/ONU, 1998), que estabelece 5 graus à sustentabilidade. Esses, individualmente, representam o estágio de sustentabilidade nos contextos em que se apresentam (Quadro 1).

Quadro 1 - Graus de sustentabilidade estabelecidos pelo Programa das Nações Unidas para o Desenvolvimento em 2017.

\begin{tabular}{|c|c|}
\hline Sustentabilidade & Valores \\
\hline Ideal & $0,800 \leq$ IS $\leq 1$ \\
\hline Aceitável & $0,600 \leq$ IS $\leq 0,799$ \\
\hline Média & $0,400 \leq$ IS $\leq 0,599$ \\
\hline Alerta & $0,200 \leq$ IS $\leq 0,399$ \\
\hline Crítica & $0,000 \leq$ IS $\leq 0,199$ \\
\hline
\end{tabular}

Fonte: Adaptado do PNUD/ONU (1998).

DRd - Desenvolvimento Regional em debate (ISSNe 2237-9029) 
Quanto à forma de tratamento e tabulação dos dados, este estudo baseou-se na pesquisa de Melo (2010) e Ferreira et al. (2017), que realizaram a análise desses indicadores na APA Chapada do Araripe e em uma comunidade quilombola em Abaetetuba, Pará, respectivamente. Assim, para a análise de sustentabilidade, foram atribuídos escopos específicos a cada indicador, que considerou as metodologias para a valoração evidenciadas no item 2.2, que, em resumo conferiu significância variável entre os valores de 0 e 1 , e peso igual a 1 (Quadro 2).

Quadro 2 - Indicadores de sustentabilidade considerados para o Assentamento Expedito Ribeiro, município de Santa Barbara, Pará em 2017.

\begin{tabular}{|c|c|c|c|}
\hline Dimensões & $\begin{array}{l}\text { Ind. } \\
1\end{array}$ & $\begin{array}{l}\text { Escopos/Categorias } \\
\text { Educação Ambiental }\end{array}$ & $\begin{array}{c}\text { Valoração do Índice de } \\
\text { Sustentabilidade dos Indicadores }\end{array}$ \\
\hline \multirow{4}{*}{ Ambiental } & 2 & $\begin{array}{l}\text { Saneamento básico (Acesso ao sistema de } \\
\text { esgoto, Acesso à coleta de lixo, Sistema de } \\
\text { escoamento da água) }\end{array}$ & \\
\hline & 3 & $\begin{array}{l}\text { Uso e conservação da água (Acesso à água } \\
\text { encanada, Qualidade dos cursos d'água, e } \\
\text { Áreas de lazer) }\end{array}$ & \\
\hline & 4 & Áreas verdes (proteção e qualidade) & $\operatorname{Sim}=1 ;$ Não $=0$ \\
\hline & 5 & $\begin{array}{l}\text { Atendimento a legislação (legalização, } \\
\text { plano de manejo e compensação ambiental) }\end{array}$ & $\begin{array}{l}\text { Excelente }=1 ; \text { Bom }=0,8 ; \text { Moderado }= \\
0,5 ; \text { Regular }=0,2 ; \text { Ruim }=0\end{array}$ \\
\hline \multirow{6}{*}{ Social } & 1 & $\begin{array}{l}\text { Saúde (Atendimento médico; Serviço de } \\
\text { saúde; Periodicidade do atendimento; } \\
\text { Profissionais de saúde) }\end{array}$ & $\begin{array}{l}\text { Excelente }=1 ; \text { Bom }=0,8 ; \text { Moderado }= \\
0,5 ; \text { Regular }=0,2 ; \text { Ruim }=0\end{array}$ \\
\hline & 2 & $\begin{array}{l}\text { Educação (Nível de educação oferecido na } \\
\text { comunidade; Transporte escolar; Qualidade } \\
\text { dos serviços educacionais) }\end{array}$ & $\begin{array}{l}\text { Excelente }=1 ; \text { Bom }=0,8 ; \text { Moderado }= \\
0,5 ; \text { Regular }=0,2 ; \text { Ruim }=0\end{array}$ \\
\hline & 3 & Habitação & $\begin{array}{l}\text { Excelente }=1 ; \text { Bom }=0,8 ; \text { Moderado }= \\
0,5 ; \text { Regular }=0,2 ; \text { Ruim }=0\end{array}$ \\
\hline & 4 & Segurança & $\begin{array}{l}\text { Excelente }=1 ; \text { Bom }=0,8 ; \text { Moderado }= \\
0,5 ; \text { Regular }=0,2 ; \text { Ruim }=0\end{array}$ \\
\hline & $\begin{array}{l}5 \\
1\end{array}$ & $\begin{array}{l}\text { Acesso a Políticas Públicas para } \\
\text { provimento de Serviços Básicos } \\
\text { Acesso ao Conselho de Meio Ambiente }\end{array}$ & $\begin{array}{l}\text { Excelente }=1 ; \text { Bom }=0,8 ; \text { Moderado }= \\
0,5 ; \text { Regular }=0,2 ; \text { Ruim }=0 \\
\text { Sim }=1 ; \text { Não }=0\end{array}$ \\
\hline & 2 & Cooperativas/Associações & $\operatorname{Sim}=1 ;$ Não $=0$ \\
\hline \multirow[t]{2}{*}{ Institucional } & 3 & $\begin{array}{l}\text { Assistência técnica (auxílio e parceria com } \\
\text { instituições de pesquisa e fomento) }\end{array}$ & $\operatorname{Sim}=1 ;$ Não $=0$ \\
\hline & 4 & $\begin{array}{l}\text { Assistência social (CRAS; controle de } \\
\text { endemias etc.) }\end{array}$ & $\operatorname{Sim}=1 ;$ Não $=0$ \\
\hline \multirow[t]{2}{*}{ Econômica } & 1 & Atividades Produtivas & $\begin{array}{l}\text { Não agrícola }=0 ; \text { Agr. ou Ext. }=0,5 ; \\
\text { Agr. }+ \text { Ext. }=1\end{array}$ \\
\hline & 2 & Atividades Complementares & $\operatorname{Sim}=1 ;$ Não $=0$ \\
\hline
\end{tabular}

Fonte: Autores (2018).

Legenda: Ind. = Indicador

Cada uma das dimensões que compõem o ISG deste estudo foi calculada separadamente, com base em suas categorias, de modo a estipular valores e estabelecer índices independentes, conforme a equação 1.

DRd - Desenvolvimento Regional em debate (ISSNe 2237-9029) 


$$
I S i=1 / \sum \text { peso } \sum_{i=1}^{n}(\text { Ii } x \text { peso })
$$

Onde, ISi é o valor calculado para o i-nésimo índice; i até n são os números de índices; Ii refere-se à cada um dos indicadores analisados, considerando-se o peso atribuídos a cada um deles. Revelando-se os índices de sustentabilidade das quatro dimensões, foram realizados os cálculos para mensurar ISG e o grau de sustentabilidade das comunidades, obtidos através da expressão 2 (FERREIRA et al., 2017; NASCIMENTO; ARAÚJO, 2008).

$$
I S G=1 / K \sum_{i=1}^{k} I S i
$$

Onde, ISG refere-se à Índice de Sustentabilidade Global; ISi à Valor calculado para o i-ésimo índice; i até k são os números de índices; e $\mathrm{N}$ é o número de indicadores. Os dados coletados pela observação participante foram analisados utilizando a Análise do Conteúdo, pois, conforme Bardin (1979, p. 42), é definida como:

$$
\begin{aligned}
& \text { um conjunto de técnicas das comunicações visando obter, por procedimentos, } \\
& \text { sistemáticos e objetivos de descrição do conteúdo das mensagens, indicadores } \\
& \text { (quantitativos ou não) que permitam a inferência de conhecimentos relativos às } \\
& \text { condições de produção/recepção (variáveis inferidas) destas mensagens. }
\end{aligned}
$$

Assim, falas, fotografias e impressões dos pesquisadores a respeito da realidade local são usadas na discussão.

\section{RESULTADOS E DISCUSSÃO}

\section{1 ÍNDICES DE SUSTENTABILIDADE DAS DIMENSÕES}

\subsection{1 Índice de Sustentabilidade Ambiental (ISA)}

$\mathrm{Na}$ dimensão ambiental o índice de sustentabilidade obtido para o Assentamento Expedito Ribeiro, teve o valor de 0,74 (Tabela 1), indicando que a sustentabilidade ambiental no assentamento, pode ser considerada aceitável, visto que o valor ficou entre o intervalo $0,600 \leq$ IS $\leq 0,799$. Foi observado que os indicadores Uso e Conservação da Água e Educação Ambiental evidenciaram os valores mais elevados (0,88 e 1,00, respectivamente), o que deve ter contribuído para o total do Índice de Sustentabilidade obtido para esta dimensão (Tabela 1). 
Tabela 1 - Resultados dos indicadores de sustentabilidade da dimensão ambiental para o assentamento Expedito Ribeiro.

\begin{tabular}{cclc}
\hline Dimensão & Indicador & Indicadores de Sustentabilidade & $\begin{array}{c}\text { Índices dos Indicadores de } \\
\text { Sustentabilidade }\end{array}$ \\
\hline & $\mathbf{1}$ & Educação Ambiental & 1,00 \\
\multirow{3}{*}{ AMBIENTAL } & $\mathbf{2}$ & Saneamento básico e coleta de lixo & 0,22 \\
& $\mathbf{3}$ & Uso e conservação da água & 0,88 \\
& $\mathbf{4}$ & Áreas verdes & 0,82 \\
& $\mathbf{5}$ & Legislação ambiental & 0,79 \\
\hline
\end{tabular}

Fonte: Autores (2018).

Quanto à categoria Uso e Conservação da Água é importante destacar que a percepção dos interlocutores sobre a qualidade da água encanada que eles utilizam (proveniente de poços) e a qualidade dos rios e córregos próximos ao assentamento, foi considerada muito boa por todos os indivíduos ouvidos, tendo médias de 0,93 e 0,88 , respectivamente. Um outro fator analisado, dentro dessa categoria, foi o da percepção sobre as áreas de lazer, pois, notouse que as áreas de lazer mencionadas pelos habitantes são os rios, córregos e igarapés próximos ao assentamento.

O pior índice encontrado para um indicador de sustentabilidade no assentamento estudado foi o de Saneamento básico e coleta de lixo $(0,22)$. Nessa categoria, a coleta de lixo foi considerada péssima $(0,04)$, sendo que muitos relataram que não existe a coleta dentro do assentamento, de tal forma que os habitantes do local só têm a opção de queimar ou carregar por alguns quilômetros o seu lixo até o distrito de Pau d'Arco. A qualidade de esgotamento sanitário $(0,24)$ e a qualidade do escoamento superficial $(0,38)$ também obtiveram índices baixos.

De modo a tentar compensar os danos ambientais causados pela não coleta de resíduos sólidos, muitos dos moradores relataram que buscam fazer a compostagem com os resíduos orgânicos e queimar somente aquilo que eles sabem que não possui mais uso. Em relação ao esgotamento sanitário, a maior parte dos habitantes relataram que possuem fossa em suas residências, diminuindo o impacto causado ao ambiente natural local.

Os índices de Educação Ambiental, Áreas Verdes e Legislação Ambiental obtiveram resultados considerados ideais ou bastante próximos do ideal (Tabela 1). Isso foi decorrente, possivelmente, ao fato de que nesse assentamento a presença e atuação das associações dos assentados é atuante, de acordo com os residentes. Sendo que, existe também nesse assentamento a influência de instituições públicas ambientais e de ensino (EMBRAPA, CAMTA, Universidade de Tóquio, EMATER, UFPA, UEPA) que trabalham em conjunto com a associação para melhorar a qualidade ambiental da área.

É válido mencionar que alguns dos lotes desse assentamento possuem SAFs que atribuem um grande valor ambiental, já que agregam características produtivas com características de conservação florestal. Para análise dos dados e geração dos índices, neste estudo, a presença de SAF na propriedade foi considerada como uma técnica de manejo sustentável e, também, um recurso de compensação ambiental.

Quanto ao ISA obtido, que indica sustentabilidade aceitável (ISA=0,74) para o Assentamento Expedito Ribeiro, ressalta-se que tal valor, em comparação com estudos

DRd - Desenvolvimento Regional em debate (ISSNe 2237-9029) 
prévios realizados no Estado do Pará, foi considerado superior aos encontrados por Ferreira et al. (2017) na comunidade quilombola África em Abaetetuba e por Rêgo (2013) na Área de Preservação Ambiental (APA) da ilha do Combú, cujos valores foram 0,37 e 0,466, respectivamente. Apesar de serem localidades consideradas próximas, em relação a dimensão territorial do Estado do Pará, percebe-se que os habitantes do assentamento Expedito Ribeiro possuem uma melhor percepção quanto às características ambientais que lhes rodeiam do que as observadas nos estudos de Ferreira et al. (2017) e Rêgo (2013).

\subsection{2 Índice de Sustentabilidade Social (ISS)}

$\mathrm{Na}$ categoria de ISS os indicadores analisados tentaram abordar questões relacionadas aos serviços públicos prestados aos moradores do assentamento, além disso, também foi perguntado sobre as condições de habitação dos assentados de maneira geral (Tabela 2).

Tabela 2 - Resultados dos indicadores de sustentabilidade da dimensão social para o assentamento Expedito Ribeiro.

\begin{tabular}{cccc}
\hline \multirow{2}{*}{ Dimensão } & Indicador & \multicolumn{1}{c}{$\begin{array}{c}\text { Indicadores de } \\
\text { Sustentabilidade }\end{array}$} & $\begin{array}{c}\text { Índices dos Indicadores de } \\
\text { Sustentabilidade }\end{array}$ \\
\cline { 2 - 2 } & $\mathbf{1}$ & Saúde & 0,95 \\
\multirow{2}{*}{ SOCIAL } & $\mathbf{2}$ & Educação & 0,58 \\
& $\mathbf{3}$ & Habitação & 0,59 \\
& $\mathbf{4}$ & Segurança & 0,38 \\
& $\mathbf{5}$ & Políticas Públicas & 0,51 \\
\hline
\end{tabular}

Fonte: Autores (2018).

O ISS no Assentamento Expedito Ribeiro obteve valor igual a 6,0 indicando que o referido assentamento pode ser considerado no grau de aceitável $(0,600 \leq$ IS $\leq 0,799)$ (Quadro 1). O indicador de qualidade do serviço público de Saúde prestado para o assentamento, foi o único indicador que obteve valor considerado no grau Ideal $(0,95)$, ficando no intervalo de $0,800 \leq$ IS $\leq 1$ (Quadro 1). Quanto a isso, os interlocutores afirmaram que há atendimento de saúde constante e permanente, no assentamento, em que os médicos vão até a sede da associação de duas a três vezes por semana e prestam o serviço indiscriminadamente aos habitantes do local. Nesse assentamento, há também o acompanhamento do programa de Serviço de Saúde da Família, do Governo Federal, que promove a saúde da população, por meio de ações básicas, para evitar que as pessoas fiquem doentes (SECRETARIA DE POLITICAS DE SAÚDE, 2000), mantendo o controle sobre a saúde dos habitantes local.

Os indicadores Habitação, Educação e Políticas Públicas locais identificados no assentamento obtiveram valores considerados medianos $(0,59 ; 0,58$ e 0,51 , respectivamente (Tabela 2). Os valores mencionados indicam o nível de sustentabilidade no grau médio para o assentamento estudado, visto que esses valores ficaram no intervalo $0,400 \leq$ IS $\leq 0,599$ (Quadro 1). O valor atribuído à educação pode ser decorrente do fato de que os moradores relataram que não há escolas em nenhum nível formal de educação dentro do assentamento, mas o ônibus escolar local, transporta os estudantes de casa para a escola todos os dias. Os interlocutores demonstraram estar bastante satisfeitos com o serviço do ônibus escolar, 
entretanto ainda almejam a inserção de uma escola dentro da área do assentamento, de tal forma que seja possibilitado o acesso à educação para todas as pessoas, independentemente da idade, e mais próxima das residências da área estudada.

Embora ainda não se observe muitas casas de alvenaria e as condições de saneamento básico sejam precárias no local, os moradores demonstraram alta satisfação com a qualidade de suas moradias (Figura 2). Isto se justifica pelo fato de que muitos dos interlocutores não possuíam casa ou terreno próprio para residir com suas famílias e/ou ter fonte de renda e subsistência antes da existência do assentamento. Além disso, conforme os relatos, a vizinhança esparsa e a grande quantidade de vegetação transformam os terrenos em verdadeiros sítios, favorecendo a integração Homem-Natureza, o que eleva a sensação de bem-estar dos moradores, uma vez que, dentre outras vantagens de morar no assentamento, enaltecem como as principais o conforto térmico e a qualidade do ar do local.

Figura 2 - Residência de uma das moradoras mais antigas do assentamento

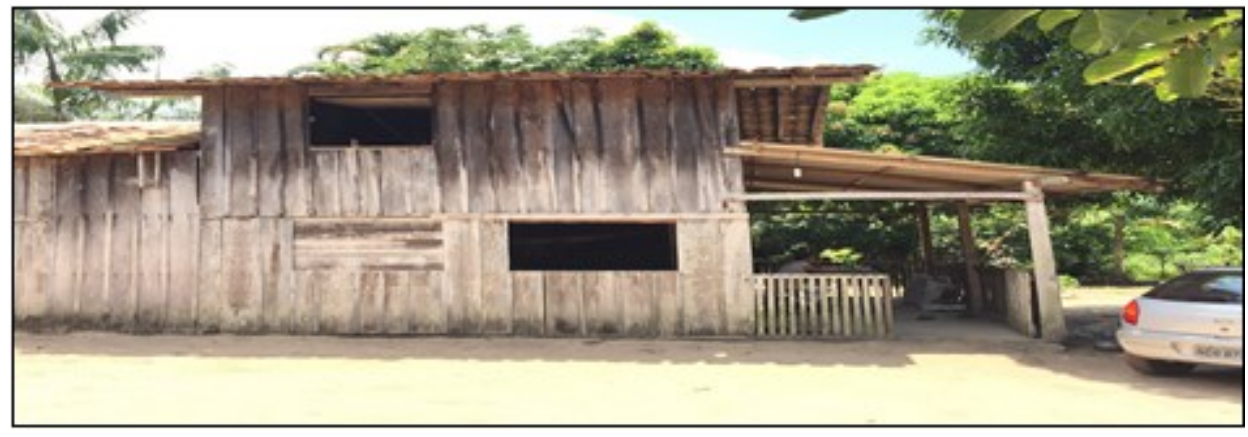

Fonte: Autores (2018).

O pior resultado encontrado dentro do ISS foi o do indicador de qualidade de segurança pública (Tabela 2). Os interlocutores relataram que existem rondas policiais dentro do assentamento, porém essas ocorrem com pouca frequência, o que facilita a ocorrência de crimes, como o assalto às residências.

Com o valor do ISS de 0,60, considerado um valor médio para o assentamento Expedito Ribeiro, constata-se que esse valor foi superior aos 0,41 encontrados por Ferreira et al. (2017) e o encontrado por Rêgo (2013) que foi de 0,466, para as localidades estudadas por esses autores. Em ambas localidades, há uma situação de quase alerta, enquanto que no assentamento deste estudo, é possível perceber a existência de atuação de políticas de assistência básica, evidenciando que o assentamento Expedito Ribeiro se encontra em uma situação vantajosa, quando comparado a outras localidades dentro do estado do Pará.

\subsection{3 Índice de Sustentabilidade Institucional (ISI)}

O ISI foi considerado ideal em três parâmetros: assistência social, conselho de meio ambiente e assistência técnica. Já o parâmetro de presença e atuação de cooperativas, apresentou nível médio (Tabela 4).

DRd - Desenvolvimento Regional em debate (ISSNe 2237-9029) 
Tabela 3 - Resultados dos indicadores de sustentabilidade da dimensão institucional para o assentamento Expedito Ribeiro.

\begin{tabular}{cccc}
\hline \multirow{2}{*}{ Dimensão } & Indicador & \multicolumn{1}{c}{$\begin{array}{c}\text { Indicadores de } \\
\text { Sustentabilidade }\end{array}$} & $\begin{array}{c}\text { Índices dos Indicadores de } \\
\text { Sustentabilidade }\end{array}$ \\
\hline \multirow{2}{*}{ INSTITUCIONAL } & $\mathbf{1}$ & Conselho de Meio Ambiente & 0,91 \\
& $\mathbf{2}$ & Associações e Cooperativas & 0,73 \\
& $\mathbf{3}$ & Assistência Técnica & 0,91 \\
& $\mathbf{4}$ & Assistência Social & 1,00 \\
\cline { 2 - 3 } & \multicolumn{2}{c}{ Índice de Sustentabilidade Institucional (ISI) } & $\mathbf{0 , 8 4}$ \\
\hline
\end{tabular}

Fonte: Autores (2018).

Isso é decorrente, possivelmente, devido à presença de instituições atuantes dentro do assentamento, pois, os habitantes locais possuem satisfação com o apoio prestado a eles, tanto por atuações governamentais (com o CRAS), quanto pelas assistências técnicas prestadas por instituições municipais, governamentais e federais. Assim como, por instituições de outros países, como o caso da Universidade de Tóquio, que auxiliou os habitantes na elaboração dos primeiros SAFs. Em vista desse apoio e para angariar mais incentivos, os assentados montaram uma associação, denominada "Associação dos Trabalhadores Rurais Agroecológico Expedito Ribeiro", que dispõe de uma sede administrativa, um anexo para a realização de reuniões, treinamentos e ações de diversas naturezas e uma área comum para plantio (Figura X).

Figura 3 - Associação dos assentados em Expedito Ribeiro. (A) Sede Administrativa. (B) Área de reuniões e ações em geral.

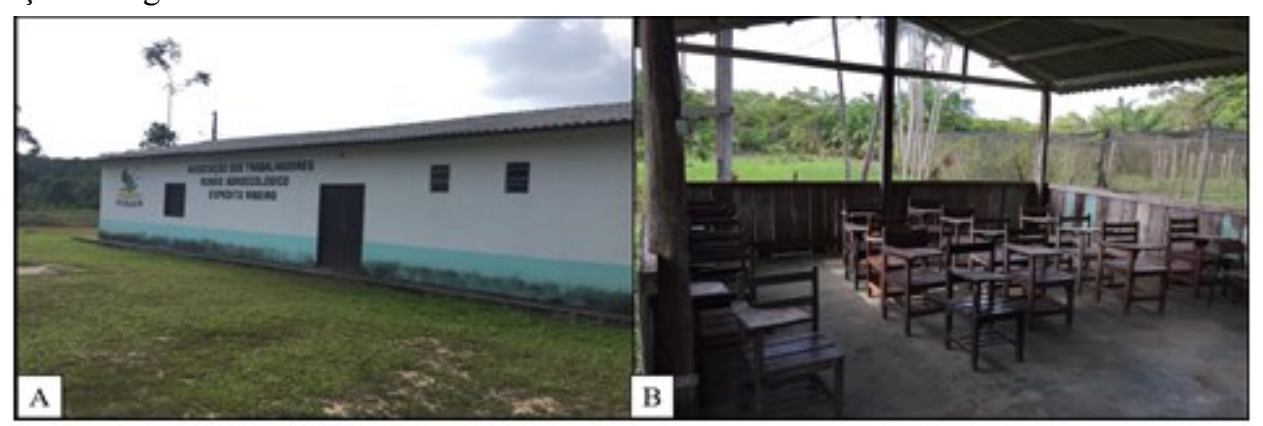

Fonte: Autores (2018).

O valor encontrado para esse índice foi de 0,89 , o mais alto entre os quatro índices analisados nesse estudo. Esse valor foi superior ao encontrado por Ferreira et al. (2017) e Rêgo (2013), 0,43 e 0,450, respectivamente. Isso demonstra que os habitantes percebem a existência de uma grande quantidade de serviços que são prestados aos moradores locais, como à assistência social e técnica, além de uma boa atuação das associações existentes no local. 


\subsection{4 Índice de Sustentabilidade Econômico (ISE)}

Os indicadores de sustentabilidade econômico no assentamento estudado mostraram que a maior parte dos assentados moradores consultados faz algum tipo de uso da terra em seu lote, porém o valor mais alto do índice só foi atribuído às pessoas que realizam dois tipos de atividades analisadas (agrícola e extrativista), o valor do índice encontrado foi de 0,64 , valor considerado aceitável. Muitos moradores possuem hortas, roçados (mandioca, pimenta ou outros vegetais) e/ou SAFs em seus terrenos, e utilizam os produtos provenientes destes para alimentação familiar e/ou como fonte de renda (Figura 4). Aqueles que não possuem terra para plantio, trabalham ou auxiliam na plantação de outros assentados em troca de algum benefício.

Figura 4 - Horta na propriedade de uma moradora do assentamento estudado.

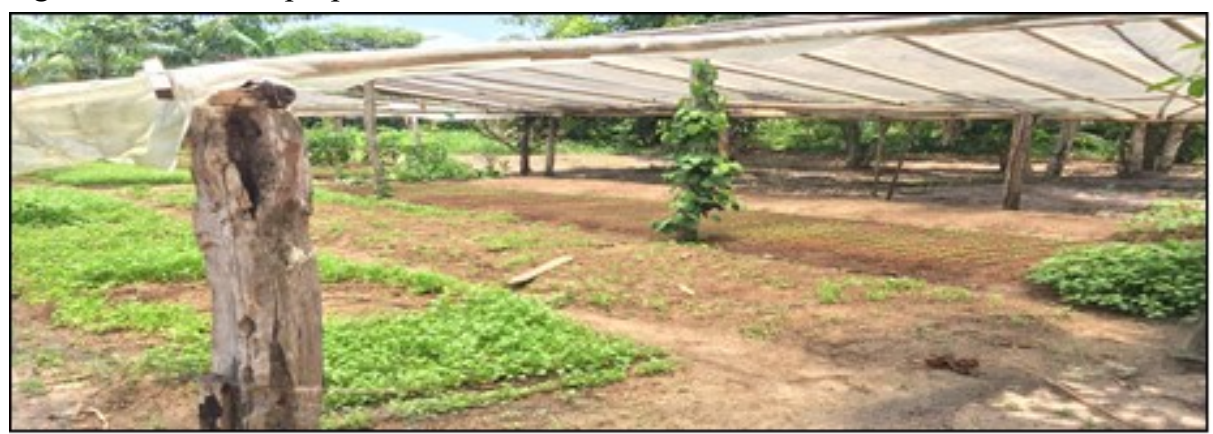

Fonte: Autores (2018).

Dentre as atividades complementares, foi mencionada pelos assentados a comercialização de carvão (não extraído do lote), de produtos (cosméticos ou utensílios para o lar) via catálogo ou de alguns animais (galinha, peru, peixes) em datas festivas (Festividade de Nossa Senhora de Nazaré - Círio, Semana Santa). O índice encontrado para esse tipo de atividade foi de 0,55 , considerado um valor mediano (Tabela 3 ).

Tabela 4 - Resultados dos indicadores de sustentabilidade da dimensão econômica para o assentamento Expedito Ribeiro.

\begin{tabular}{cclc}
\hline Dimensão & Indicador & Indicadores de Sustentabilidade & $\begin{array}{c}\text { Índices dos Indicadores de } \\
\text { Sustentabilidade }\end{array}$ \\
\hline \multirow{2}{*}{ ECONÔMICA } & $\mathbf{1}$ & Atividades produtivas & 0,64 \\
& $\mathbf{2}$ & Atividades complementares & 0,55 \\
\hline & \multicolumn{1}{c}{ Índice de Sustentabilidade Econômica (ISE) } & $\mathbf{0 , 5 9}$ \\
\hline
\end{tabular}

Fonte: Autores (2018).

O valor de ISE para o assentamento foi de 0,59, considerado mediano. Assim, constatou-se que esse valor foi superior aos 0,366 obtido na comunidade que vive na ilha do Combú por Rêgo (2013). Porém, notou-se que os valores foram inferiores aos 0,65 encontrado na comunidade quilombola de Abaetetuba, por Ferreira et al. (2017).

A presença de SAFs dentro do assentamento Expedito Ribeiro foi um diferencial quando os valores de ISE foram comparados com os dos moradores da ilha do Combú. Assim como no estudo de Ferreira et al. (2017), notou-se que no assentamento Expedito Ribeiro não há uma tendência de as pessoas buscarem rendas complementares e tornarem essa renda sua

DRd - Desenvolvimento Regional em debate (ISSNe 2237-9029) 
principal, ou seja, nos dois casos a renda principal são a agrícola e/ou extrativista, sem que exista grande impacto da renda alternativa na vida dessas pessoas.

\section{2 ÍNDICE DE SUSTENTABILIDADE GLOBAL (ISG)}

A realização dos cálculos dos índices de sustentabilidade das dimensões por escopo, apresentados acima, corroboraram para a elaboração do ISG, elaborado através da média desses valores. Os resultados que constituíram o ISG e o valor final deste para o assentamento rural Expedito Ribeiro são apresentados na Tabela 5.

Tabela 5 - Índice de Sustentabilidade Global encontrado no Assentamento Expedito Ribeiro.

\begin{tabular}{cc}
\hline Dimensão de Sustentabilidade & Índices de Sustentabilidade das Dimensões \\
\hline Ambiental & 0,74 \\
Social & 0,60 \\
Institucional & 0,89 \\
Econômica & 0,59 \\
\hline Índice De Sustentabilidade Global (ISG) & $\mathbf{0 , 7 0}$ \\
\hline
\end{tabular}

Fonte: Autores (2019).

Para o Assentamento Expedito Ribeiro, o ISG obtido, indica uma sustentabilidade global aceitável (ISG $=0,70)$. Tal valor, apresenta resultado similar ao estudo de Silva, Cândido e Lira (2013) em apenas um dos seis assentamentos agrícolas participantes do estudo. Já em relação ao estudo de Granda e Lima (2006), se demonstra maior ao índice calculado para uma pequena área de mineração artesanal de coquina, no Equador, que obtiveram valor de ISG $(0,61)$. Além desse estudo, outras pesquisas, que utilizaram metodologias similares, como na APA do Combú, Belém, Pará (RÊGO, 2013); e na Comunidade Quilombola África, Abaetetuba, Pará (FERREIRA et al., 2017), obtiveram resultados expressando grau médio de sustentabilidade $(0,46)$, inferiores aos encontrados no presente estudo.

O ISG do assentamento agrícola aqui estudado, explicita um relevante cenário de acesso a políticas públicas voltadas às populações domiciliadas em loteamentos a margem da legalização judicial e tributária. Notou-se que, com base na observação dos relatos dos moradores, as associações rurais da localidade são fundamentais para o provimento de serviços básicos e manutenção da qualidade de vida no assentamento. Uma vez que realizam parcerias com iniciativas públicas e privadas, além de defender e mediar sobre os interesses dos residentes junto ao poder público. Conforme os dizeres de João ${ }^{7}$ :

"Aqui, nós só tem médico porque a associação conseguiu um contato com a universidade e eles trazem uma turma para consultar o povo, lá na sede [espaço físico da sede da associação]”. (João, 44 anos, agricultor).

Como reflexo disso, ressalta-se o ISI com grau ideal, reafirmando a forte atuação institucional na área, confiança e filiação dos moradores nas associações. De acordo com o SENAR (2011), a proposta do associativismo das comunidades rurais visa ampliar as

\footnotetext{
${ }^{7}$ No intuito de assegurar o compromisso do anonimato dos interlocutores, afixado de acordo com o TCLE, os nomes dos moradores são fictícios.
}

DRd - Desenvolvimento Regional em debate (ISSNe 2237-9029) 
oportunidades de acesso aos interesses e necessidades relacionados à vida da comunidade, além de fortalecer as iniciativas produtivas e comerciais dos moradores.

O ISA foi considerado aceitável, ressaltando-se que, mesmo com toda influência das associações, a questão da falta de atenção nos serviços de saneamento básico e coleta de lixo ainda é um problema bastante questionado pelos moradores. Uma vez que não há coleta dos resíduos pela prefeitura municipal, estações de tratamento de esgoto e tubulações para oferta de água encanada, o que obriga aos moradores a perfuração de poços artesianos e queima dos rejeitos domiciliares.

Embora se expresse como indicador aceitável, linha limítrofe com o grau médio, constatou-se que a maioria dos escopos que compunham o ISS se apresentam de forma deficitária à população. O assentamento é desprovido de posto de saúde ou unidade da estratégia saúde da família, mas todos têm acesso à saúde, ofertada em parceria das associações rurais com universidades. Quanto à educação, destaca-se a inexistência de escolas, porém é realizado o serviço de transporte escolar gratuito, por parte da prefeitura municipal, até as instituições mais próximas, localizadas na vila de Pau d'Arco. As habitações foram construídas na terra loteada invadida, em sua maioria, com madeira proveniente de árvores da própria comunidade, sendo raras as casas de alvenaria.

O ISE foi considerado médio, observando-se que todos na comunidade possuem energia elétrica e espaço para realização de atividades agrícolas, porém uma queixa bastante unânime da população são os baixos preços de venda da produção. Essa situação se materializa na faixa salarial média de até um salário mínimo, o que gera descontentamento nos residentes, refletindo no valor do índice abaixo dos demais. Alguns moradores utilizam o modelo de consórcio de culturas em Sistemas Agroflorestais - SAFs, projetados em parceria com os agricultores a CAMTA e técnicos da EMATER, o que garante renda aos produtores durante quase todo o ano a longo prazo, ao integrar espécies frutíferas, anuais e semi-perenes, e florestais. A maioria das pessoas abordadas por este estudo também realiza atividades para complementação de renda, como comércio de animais em feiras (patos para a festividade do Círio de Nazaré, realizado em Belém) e carvão.

\section{CONSIDERAÇÕES FINAIS}

O uso de indicadores de sustentabilidade para identificação, percepção, caracterização e acompanhamento da realidade de um espaço geográfico, como proposto na presente pesquisa, analisado sobre suas amplas dimensões, tem sido um forte aliado para a tomada de decisões nas esferas de planejamento e execução de políticas públicas, voltadas ao uso da terra e à qualidade de vida humana. Os índices obtidos indicam haver sustentabilidade na área estudada, de acordo com a maioria das dimensões analisadas, incluindo ao se realizar um apanhado geral dessas, o que destaca um cenário de acesso às políticas públicas e satisfação da população com as condições de vida a que estão sujeitas no assentamento Expedito Ribeiro.

O uso de indicadores de sustentabilidade para identificação, percepção, caracterização e acompanhamento da realidade de um espaço geográfico, como proposto na presente pesquisa, analisado sobre suas amplas dimensões, tem sido um forte aliado para a tomada de

DRd - Desenvolvimento Regional em debate (ISSNe 2237-9029)

v. 9, p. 59-76, 2019. 
decisões nas esferas de planejamento e execução de políticas públicas, voltadas ao uso da terra e à qualidade de vida humana. Os índices obtidos indicam haver sustentabilidade na área estudada, de acordo com a maioria das dimensões analisadas, incluindo ao se realizar um apanhado geral dessas. O que destaca um cenário de acesso às políticas públicas e satisfação da população com as condições de vida a que estão sujeitas no assentamento Expedito Ribeiro.

É possível verificar, a partir dos resultados, a contribuição considerável das associações rurais na melhoria das condições de vida das pessoas do assentamento. Pois, ao mediar os interesses dos moradores junto ao poder público e estabelecer contatos com instituições privadas, oportunizam o suprimento das necessidades sociais básicas e auxílio no desenvolvimento de atividades econômicas.

Como estratégia para melhorar a sustentabilidade do assentamento agrícola estudado, faz-se necessária a implementação de assistência especializada que auxilie a população a traçar planos para melhor beneficiar sua produção, visando maximizar as oportunidades de renda para os moradores. Isso é necessário, em decorrência de que a dimensão econômica, para o assentamento, apresentou maior deficiência na análise de sustentabilidade. Portanto, incentivar a produção de polpa de frutas, elaboração de geleias de frutas, produção de chocolates, extração de produtos derivados da mandioca e etc., poderiam ser medidas implementadas para melhorar a condição de sustentabilidade econômica do assentamento estudado.

Para a comunidade do assentamento Expedito Ribeiro, pode-se admitir que seria de grande importância o desenvolvimento de estudos como: a avaliação da viabilidade econômica dos sistemas agrícolas cultivados pelos moradores; a realização de um levantamento fitossociológico das espécies vegetais cultivadas; a determinação da cadeia produtiva dos produtos beneficiados (geleias, chocolates e etc.), os quais somados aos dados obtidos nesta pesquisa, corresponderiam a uma grande contribuição para a população. Pois evidenciaria melhores práticas de manejo, arranjamento e cultivo agrícola, além de promover o estímulo ao acesso a políticas públicas, ao desenvolvimento e a regularização documental do assentamento.

\section{REFERÊNCIAS}

ALBUQUERQUE, U. P.; LUCENA, R. F. P.; CUNHA, L. V. F. C. Métodos e técnicas na pesquisa etnobiológica e etnoecológica. Recife, PE: NUPPEA, 2010.

ALMEIDA, C. M. V. C.; MÜLLER, M. W.; SENA-GOMES, A. R. Sistemas Agroflorestais com o cacaueiro como alternativa sustentável ao desenvolvimento no Estado de Rondônia, Brasil. In: IV Congresso Brasileiro de Sistemas Agroflorestais. 2002, Ilhéus, BA. Anais... Ilhéus, BA, 2002.

BANDY, D.; GARRATY, D. P.; SANCHES, P. El problema mundial de la agricultura de tala y quema. Agroforesteria en las Americas, v. 1, n. 3, p. 14-20, 1994.

BARDIN, L. Análise de conteúdo. Lisboa: Edições 70, 1979. 
BENETTI, L. B. Avaliação do índice de desenvolvimento sustentável do município de Lages (SC) através do método do Painel de Sustentabilidade. 2006. 215f. Tese (Doutorado em Engenharia Ambiental) - Curso de Pós-Graduação em Engenharia Ambiental, Universidade Federal de Santa Catarina, 2006.

BURKHARD, B.; MÜLLER, F. Driver-Pressure-State-Impact-Response. Encyclopedia of Ecology, p. 967-970, 2008.

CARVALHO, J. P. L.; SILVA, L. M. S. Indicadores de sustentabilidade na compreensão de processo de adaptação de agroecossistemas familiares. RAF Agricultura Familiar: Pesquisa, Formação e Desenvolvimento, v. 11, n. 1, 2015.

CARVALHO, J. R. M.; CURI, W. W. F; CARVALHO, E. K. M. A; CURI, R. C. Proposta e validação de indicadores hidroambientais para bacias hidrográficas: estudo de caso na subbacia do alto curso do Rio Paraíba, PB. Revista Sociedade e Natureza, v. 23, n. 2, ago. 2011.

COUTO, O. F. V. Geração de um índice de sustentabilidade ambiental para bacias hidrográficas em áreas urbanas através do emprego de técnicas integradas de geoprocessamento. 2007. Dissertação (Mestrado) no Instituto de Geociências, Universidade Federal do Rio Grande do Sul. Porto Alegre, 2007.

ENDO, A. et al. A review of the current state of research on the water, energy, and food nexus. Journal of Hydrology: Regional Studies, v. 11, p. 20-30, 2017.

FEIL, A. A.; SCHREIBER, D. Análise da estrutura e dos critérios na elaboração do índice de Sustentabilidade. Sustentabilidade em debate, v. 8, n. 2, p. 30-43, 2017.

FERREIRA, P. F. et al. Indicadores de sustentabilidade na comunidade quilombola África, município de Abaetetuba, Pará, Brasil. Revista Espacios, v. 38, n. 8, 2017.

FONSECA, K. O. et al. Análise econômica de investimentos em sistema agroflorestal no assentamento dos trabalhadores rurais Expedito Ribeiro, município de Santa Bárbara. In: IV SIMPÓSIO DE ESTUDOS E PESQUISAS EM CIÊNCIAS AMBIENTAIS NA AMAZÔNIA, Belém, 2015. Anais... Universidade do Estado do Pará: Belém, PA, 2015.

FRANCA, L. P. Indicadores ambientais urbanos: revisão da literatura. São Paulo: Parceria $21,2001$.

GEIJZENDORFFER, I. R. et al. Ecosystem services in global sustainability policies. Environmental Science \& Policy, v. 74, p. 40-48, 2017.

GOMES, P. R; MALHEIROS, T. F. Proposta de análise de indicadores ambientais para apoio na discussão da sustentabilidade. Revista Brasileira de Gestão e Desenvolvimento Regional, Taubaté, v. 8, n. 2, p. 151-169, 2012.

GRANDA, W. J. V.; LIMA, H. M. Aplicação do Índice Global de Sustentabilidade na explotação de coquina na Península de Santa Elena. Rem: Revista da Escola de Minas, v. 59, n. 3, p. 323-327, 2006. 
HOLDEN, E.; LINNERUD, K.; BANISTER, D. The imperatives of sustainable development. Sustainable Development, v. 25, n. 3, p. 213-226, 2016.

IBGE - Instituto Brasileiro de Geografia e Estatística. Cidades. 2010. Disponível em:

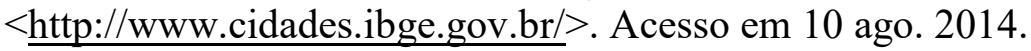

LARCOM, S.; VAN GEVELT, T. Regulating the water-energy-food nexus:

Interdependencies, transaction costs and procedural justice. Environmental Science \& Policy, v. 72, p. 55-64, 2017.

MAES, J.; JACOBS, S. Nature-Based Solutions for Europe's Sustainable Development. Conservation Letters, v. 10, n. 1, p. 121-124, 2017.

MELO, V. V. A. Inserção das unidades e conservação na sustentabilidade regional: o caso do submédio São Francisco. 2010. 231 f. Dissertação (Mestrado em Desenvolvimento e Meio Ambiente), Universidade Federal de Pernambuco, Recife, 2010.

MORA, J. C. R.; LINARES, P. Exergy as a global energy sustainability indicator. A review of the state of the art. Renewable and Sustainable Energy Reviews, v. 33, p. 427-442, 2014.

NASCIMENTO, S. C. O. do; ARAÚJO, R. C. P. Avaliação da Sustentabilidade do Projeto de Piscicultura Curupati-peixe no açude Castanhão, Jaguaribara-CE. In: XLVI Congresso da sociedade brasileira de economia, administração e sociologia rural, Rio Branco - Acre, 20 a 23 de jul., 2008.

NERI, A. C.; DUPIN, P.; SÁNCHEZ, L. E. A pressure-state-response approach to cumulative impact assessment. Journal of Cleaner Production, v. 126, p. 288-298, 2016.

PNUD/ONU. Atlas do Desenvolvimento Humano no Brasil. Edição em CD-ROM. Brasília, 1998.

RABELO, L. S.; LIMA, P. V. P. S. Indicadores de sustentabilidade: a possibilidade da mensuração do desenvolvimento sustentável. REDE: Revista Eletrônica do PRODEMA, v. 1, n. 1, p. 55-76, 2007.

RÊGO, M. C. O uso de indicadores de sustentabilidade na gestão ambiental de unidades de conservação: estudo de caso da APA da Ilha do Combu, Belém/PA. 2013. 67f.

Dissertação (Mestrado em Ciências Ambientais) - Universidade do Estado do Pará, Belém, 2013.

SECRETARIA DE POLITICAS DE SAUDE. Departamento de Atenção Básica. Programa Saúde da Família. Revista de Saúde Pública, v. 34, n. 3, p. 316-319, 2000.

SENAR (Serviço Nacional de Aprendizagem Rural). Associações rurais: práticas asscociativas, características e formalização. Brasília: SENAR, 2011.

SILVA, M. K. D.; CÂNDIDO, G. A.; LIRA, W. S. Sustentabilidade nas práticas agrícolas adotadas em assentamentos rurais junto a pequenos produtores de mandioca. In: Anais... X Encontro da ECOECO, Vitória, Espírito Santo, Brasil, 2013.

DRd - Desenvolvimento Regional em debate (ISSNe 2237-9029) 
SINGH, R. K. et al. Development of composite sustainability performance index for steel industry. Ecological Indicators, v. 7, n. 3, p. 565-588, 2007.

SINGH, S. Sustainable development: an earnest hope. In: Environment and Sustainable Development. Springer, New Delhi, 2014. p. 23-29.

WAAS, T. et al. Sustainability assessment and indicators: Tools in a decision-making strategy for sustainable development. Sustainability, v. 6, n. 9, p. 5512-5534, 2014.

Artigo recebido em: 13/08/2018

Artigo aprovado em: 21/09/2018 